\title{
Review on the Research of Executive Compensation Stickiness
}

\author{
Aimin Zhang \\ Department of Business Administration \\ East China University of Science and Technology \\ Shanghai, China \\ amzhang@ecust.edu.cn
}

\author{
Yunshi Lu \\ Department of Business Administration \\ East China University of Science and Technology \\ Shanghai, China \\ 476930945@qq.com \\ *Corresponding author
}

\begin{abstract}
This article reviews the existing articles at home and abroad in the area of executive compensation stickiness. We found that existing articles include four aspects, which are the relationship between executive salary and performance, the existence of compensation stickiness, the influence factor and the consequence. Basing on these, we put forward the shortage of existing articles, such as imperfect design of model, multicollinearity problem. We also suggested future research direction. We concluded that future research should focus on the cause and mechanism why the relationship between performance and executive compensation is different. Scholars can extend the influence of external supervision and manager characteristic on the executive compensation stickiness and the economic outcome of compensation stickiness. This article will be useful for further research on this area.
\end{abstract}

Keywords- executive compensation stickiness; performance; salary; managerial power perspective; review

\section{INTRODUCTION}

Executive Compensation stickiness is that the marginal increase amount of top management salary when the company performance increases is much higher that the marginal decrease amount when the performance decreases (Jackson, 2008).[1] Generally speaking, it refers to that then the company performance increases, the management salary increase largely, but when the company performance drops, the management salary won't decrease in the same proportion, and sometimes it even increase rather than increasing. Foreign scholars started the research of executive compensation stickiness from 1998, but early in 1925, Baker and Taussings found this phenomenon without defining it.[2] Until 2008, Jackson defined it.

Berle and Means(1932) put forward that, separation of ownership and management control right is widespread in today's companies. Optimal Contract Perspective says that motivating managers and designing optimal salary contract are important ways to solve principle-agent contradiction. However, compensation stickiness is exactly the reflection of principle-agent contradiction. Optimal Contract Perspective can't explain now. While Managerial power perspective this. Bebchuk(2002) put forward that managers had enough motivation to use managerial power to manipulate their own salary, which is rent-seeking. Therefore, salary incentive can't solve principle-agent contradiction and it is the reflection of principle-agent contradiction. When the company performance increases, top managers will ask for salary as high as possible out of claim credit. When the company performance decreases, they disagree to decrease their salary, using economic situation and product-market competition as excuse. Obviously, compensation stickiness reflects that the salary system is imperfect from indirect side and will damage the healthy development of the entire company.

This article reviews the existing articles at home and abroad in this area in the first place, and then puts forward the shortage of existing literatures. In the end, we make some suggestion for further study.

\section{LITERATURE REVIEW OF EXECUTIVE COMPENSATION STICKINESS}

Executive compensation stickiness reflects the relationship between top managers' salary and company performance. It is the asymmetric linear relation between managers' salary and company performance (Leone, $\mathrm{Wu}$, etc, 2006). [3] Therefore, we start from the relationship between managers' salary and company performance. We conclude four aspects about executive compensation stickiness as follows: (1) Is managers' compensation related to company's performance? (2) Is executive compensation stickiness widespread? (3) What factors affect executive compensation stickiness? (4) What influence executive compensation will bring to the enterprises' behavior and performance?

\section{A. Is managers' compensation related to company's performance?}

There are a lot of literatures about whether managers' compensation and company's performance are related (sensibility), but so far there is no unified answer. Scholars generally hold two views, which are being related and being irrelevant. Foreign scholars studies in this respect earlier than that at home. In 1925, Baker and Taussings found that the relationship between salary and performance 
is very weak. When the performance fluctuates, the executive compensation remains unchanged for a long time. This assert caused a large stir in academia. Subsequently, the scholars in different countries made regression for these two variables based on different samples. They also get the same conclusion that the coefficient is not significant between the two (Tosi, etc, 2000; Bebchuk, etc, 2004). [4] Among these, Jenson and Murphy(1990)'s research is of the most important significance.[5] They took 2213 top managers' salary which are listed in the Forbes Survey during 1974 to 1986 in their sample, and calculated the sensitive coefficient between executive pay and corporate performance. Finally, they find the coefficient is significant but very small, which means it doesn't have economical meaning. They are regarded as authority in the area of executive compensation. Latter research has mostly inherited the research model of this article. Domestic early findings support no related theory (Li, 2000; Zheng and Dan, 2008). [6-7] Zhou(2000) argued that the irrelevance derived from the contraction between various stakeholders since the reform and opening up through economic analysis,[8] which gave reasonable explanation for this irrelevance.

While most scholars support no related theory, some scholars still get the results that salary and performance are positively related. Foreign scholars such as Abowd(1990), Hall and Liebman(1998) hold this view.[9-10] A lot of domestic scholars support related theory and these researches concentrate on recent ten years( $\mathrm{Du}$ and Wang, 2009; Jiang and Huang, 2011).[11] Some scholars got some interesting conclusion that the relationship would be affected by other factors. Luo and Kuang(2003) argued that the relationship between salary and performance would be affected by the type of enterprises.[12]

In conclusion, research conclusions are not the same at home and abroad, which largely depended on the selection of sample and time period. Most foreign scholars support not related theory. At home, early scholars also supported not related theory while in recent years China's listed companies executive salary has presented obvious performance sensitivity. The amount of this kind of articles which studies sensitivity is very large, but the amount of the articles which studies asymmetrical sensitivity is not very big. Therefore, the asymmetrical sensitivity, which is also called as stickiness is regarded as hot spot in this area.

\section{B. Is executive compensation stickiness widespread?}

"Stickiness" started from cost stickiness. In last 90s, Noreen and Soderstrom(1997) found cost stickiness through regression of management expense in the hospitals and called it as non-linear and asymmetrical relationship. Kenneth Calleja, Michaeal Steliaros.etc compared the cost between England, French, German and America, and verified that cost stickiness is widespread in every country. Domestic research on compensation stickiness started relatively late and also started from cost stickiness. Cost stickiness is defined as the phenomenon that "the rising amount of cost when the volume of business rises is greater than the decrease amount when the volume of business decreases" by Liu(2004). He and Liu, Wang(2009) demonstrate the existence of cost stickiness with the sample during 1994 to 2001 and 2001-2004 separately. After making a preliminary study of the "stickiness", scholars found that the asymmetric relationship existed not only in cost and revenue, but also in executive compensation and performance.

Most studies about "stickiness" concentrate on cost stickiness, but there are not very many studies about compensation stickiness. All these studies hold the same view that compensation stickiness is widespread. Scholars usually study the sensitivity between salary and performance firstly, and then go deep into whether the sensitivity is symmetric. Early in 1925, Taussings and Baker found that the relevance between salary and performance is very small and the sensibility between the two is asymmetric. Gaver and Gayer (1998) found that when performance rises salary rises, but when the performance drops, top managers are not punished using the sample of American listed companies. Leone(2006) and Jackson(2008) made an empirical regression, draw the same conclusion that stickiness existed in CEO salary using the sample period during 1992-2003 and 1992-2002 separately.

Domestic studies stared relatively late and most of them are aimed to demonstrate the existence of compensation stickiness. Research model and the way of thing is almost the same, among which Fang"s(2009) study is the most typical and the most significant.[13] Fang selected A-share firm from 2001 to 2007 as sample and made regression between executive compensation and performance. He found that the two variables are positively related. Then he Introduced virtual viable and found that the coefficient of cross multiply is very significant, thereby demonstrate the existence of compensation stickiness. Later on, Gao(2011), Xia(2014) studied the existence of compensation stickiness and draw the positive conclusion with example of A-share companies during different period.[14-15].

From above, we find that compensation stickiness is widespread both at home and in foreign capital market.

\section{What factors affect executive compensation stickiness?}

Compensation stickiness tends to reflect an impact salary system and the serious principal-agent problems in an enterprise. It is caused by not only one factor. We can control it only by finding its source.

From the perspective of enterprise itself, the industry that the company in, the property rights will result in different level of compensation stickiness. $\mathrm{Xu}$ and Liang(2012) pointed out that, the compensation stickiness of China listed companied is affected by industry factor. Executive compensation stickiness in manufacturing, transportation and warehousing, information technology is higher than that in other industries. [16] Considering the special institutional background, Firth and Peter(2006) found that executive compensation stickiness in private enterprise is higher than state-owned business. [17] Even in state-owned business, top managers in central government holding companies would pay more attention to their own identity and public opinion and be willing to decrease their salary when the performance drops because of different level of disclosure and public focus. Therefore executive compensation stickiness will be lower in central government holding companies than in local government holding companies (Bu,2012).[18] 
From the perspective of internal enterprise, the weaker the corporate governance, the bigger the management power, the easier manager can manipulate salary system, the bigger compensation stickiness is. Lai(2012) found that, corporate governance will have influence on compensation stickiness, and the bigger the size of executive board, supervisory board and the ratio of independent directors, the better the internal control, the lower the compensation stickiness.[19] On the other side, if one party alone big, which is management layer, the power will be too big, the compensation stickiness will also be very high(Gao,2011). Fang(2009) also pointed out, the independence of the board of directors would help decrease the compensation stickiness.

From the external view, the greater the regulatory power, the bigger the control power of compensation stickiness. External regulation forces include the debtor, investors and analysts which focus on company financial reports. These forces will work together on the company's compensation mechanism. Debt constraint, analyst focus and venture capital will all ease company's principal-agent contradiction, thus decrease compensation stickiness. [2021]

\section{What influence executive compensation will bring to the enterprises' behavior and performance?}

Compensation stickiness directly shows that no matter how changes of enterprise performance, executive benefits are likely to be direction of their compensation. Enterprise's behavior must be affected by the executives "self-interest" mentality, so as to damage the corporate performance. $\mathrm{Xu}(2012)$ mentioned that, the existence of executive compensation stickiness will weaken the salary incentive effect, expand the compensation gap between the executives and ordinary workers, which will result in executive payment expansion.

There are only few empirical articles about what outcomes compensation stickiness will bring about. On one hand, it is difficult to measure compensation stickiness. On the other hand, the formula to be verified is too complex to get significant results. But some scholars still get significant results. Zhang(2014) make a regression for the sample which has compensation stickiness. She found that the stickiness will have negative influence on future performance. Zeng(2009) studied the sample of listed companies from 2004 to 2007 which change the top managers and found that the bigger the compensation stickiness, the more significant the company's value change is by the management turnover.[22]

\section{INSUFFICIENT RESEARCH}

Compensation stickiness is regarded as hot spot in the area of executive compensation, but there aren't many research papers and the articles which are published in the top journals are very few. It has something to do with the shortage in the research method.

\section{A. Unreasonable design of research model}

Researching in this area usually needs a dummy variable. When performance year-on-year declines, this dummy variable equals 1 , or it equals 0 . Researches put this dummy variable and performance variable cross multiply into the research model. They determined the presence of significant according to the significance of the coefficient of it. If this coefficient is negatively related, it explains that when the performance drops, executive compensation rises obviously. But according to the definition of compensation stickiness, this is only an extreme case of stickiness. In fact, this model doesn't reflect well the concept of "marginal difference", which is the marginal increase amount of top management salary when the company performance increases is much higher that the marginal decrease amount when the performance decreases.

\section{B. Multicollinearity problems}

Most domestic scholars followed the model and way of Fang(2009). When they study the factors which affect compensation stickiness, they all add one more cross multiply into the model verifying the existence of compensation stickiness, which resulted in three variables cross multiply. This will inevitably lead to multicollinearity problem. There are no scholars who make an explanation and verify it.

\section{EXPECTATION}

We reviewed and analyzed the articles in the area of executive compensation, and we think further studies can conduct as follows:

\section{A. Delve into the cause and mechanism why the relevance between salary and performance is not unified.}

Foreign scholars generally get the conclusion that compensation and performance is not related. But in recent years, data in our country support high relevance between these two variables. What on earth accounts for it, different system background at home and abroad or different research method? Even in our country, the research outcome early and now are of great different. So from what time to start, the correlation between compensation and performance significantly start? Does it have something to do with our frequent legislative and regulatory reform? These questions are worthy to be studied and thinking deeply for future scholars.

\section{B. From the manager's own characreristics to consider its impact on compensation stickiness}

Current literatures have investigated the factors that affect compensation stickiness form corporate itself, governance structure and management power inside the company, and enterprise external supervision power. They ignored that the manager's own characteristic would have influence on compensation stickiness. China's capital market is the government-led market, so does the relationship between managers and governments have effect on compensation stickiness? Does the education background and serving time of managers have effect on maneuvering ability and then have effect on compensation stickiness? These questions have not considered by predecessors and lack rigorous empirical research.

Compensation stickiness is the embodiment of company's principle-agency conflicts in nature. The external supervision can ease the conflicts to a certain extent. So, except for creditors, investors and analysts, 
there are many supervision powers, such as disclosure of accounting information, audit supervision quality, institutional equity holding. Will these factors have effect on compensation stickiness?

\section{Expand research about the influence of compensation stickiness on corporate behavior and performance?}

Though many scholars have discussed the adverse consequences that compensation stickiness brings to the enterprises, they lack rigorous empirical demonstration. There are only influences that compensation stickiness brings to future performance and enterprise value so far. Future studies can focus on the growth, market return, which investors pay close attention to.

\section{REFERENCES}

[1] Jackson S., Lopez T \& Reitenga A. Accounting Fundamental and CEO Bonus Compensation[J]. Journal of Accounting and Public Policy.2008(27), pp.374-393.

[2] Taussings F. W.,Baker W.S..American Corpirations and their Executive: A Statistical Inquiry[J]. Quarterly Journal of Economics.1925(1), pp.1-51.

[3] Leone A, Wu J \& Zimmerman J. Asymmetric Sensitivity of CEO Cash Compensation to Stock Returns[J]. Journal of Accounting and Economics.2006(42), pp.167-192.

[4] Bebchuk, L., J. Fried. Pay without Performance: The Unfulfilled Promise of Executive Compensation[M]. Harvard University Press, Cambridge, MA.2004.

[5] Jensen, M \& Murphy. Performance Pay and Top Management Incentives[J]. Journal of Political Economy.1990(98),pp.225-264.

[6] Li ZengQuan. Incentive mechanism and enterprise performance-An empirical research based on listed companies[J]. Accounting research.2000(01), pp.24-30.

[7] Zheng XiangJie, Dan HuaZhen. Executive compensation and corporate performance in financial insurance industriy in our country[J]. Financial Theory and Practice.2008(10), pp.50-52.

[8] Zhou YeAn. Economics analysis of the relationship between manager compensation and corporate performance[J]. China Industrial Economy.2000(05), pp.60-65.

[9] Abowd, M, J. Does Performance-Based Managerial Compensation Affect Corporate Periformance?[J]. Industrial and Labor Realation Review.1990,33(4):663-691.
[10] Hall, Brian J., Jefftry B. Liebman. Are CEOS really paid like bureaucrats?[J]. Quarterly Journal of Economics.1998(7):85-107.

[11] Du XingQiang, Wang LiHua. Analysis of the influence factors of executive compensation and corporate performance correlation- based on the ownership structure, industry characteristics and ultimately control human qualitative empirical ecidence[J]. Journal of Shanghai Lixin University of Commerce.2009(01), pp.53-65.

[12] Luo YueLong, Kuang Mo.Correlations between enterprenuers reward and performance based on type differences[J]. Modern Economic Science.2003(04), pp.50-55.

[13] Fang JunXiong. Does executive compensation stickiness exist in our listed companies in China[J]. Economic Resarch.2009(03), pp.110-124.

[14] Gao WenLiang, LuoHong, Cheng PeiXian. Management Power and the Executive Compensation Stickiness[J]. Economic Survey.2011(06), pp.82-86.

[15] Xia XueHua. Debt maturity structur, nature of property right and executive compensation stickiness[J]. Technology and Economics.2013(01), pp.106-110.

[16] Xu Jian, Liang TongYin. Executive compensation stickiness and its influencing factors $[M]$. South China University of Sicience and Technology.2012.

[17] Michael Firth, Peter M.Y.Fung, Oliver M.Rui. Corporate performance and CEO compensation in China[J].Journal of Corporate Finance.2006(12):693-714.

[18] Bu DanLu, Zhang ChenYu. Nature of Property Right, Risk Performance and Compensation Stickiness[J]. China Accounting Review.2012(03), pp.325-346.

[19] Lai WeiWei, Xu HongLin. The influence of corporate governance structure on the executive compensation stickiness - An empirical research based on China listed companies[M]. Southwestern University of Finance.2012.

[20] Liu ZhongYan, Zhou ZeTao. The inflence of analysts focus on the executive compensation stickiness in listed companies[J]. Journal of North China electic power university( social and science edition).2014(01), pp.26-32.

[21] Yuan JiGuo, Zou HongYuan. Influence of venture capital on the mechanism of corporate governnance- based on the perspective of principal-agent theory[M]. Southwestern University of Finance.2013.

[22] Zeng Yi. Compensation stickiness, Executive Change and the Value of the Company[J]. Shanghai Management Science. 2009(04), PP.70-73. 